\title{
O ENSINO DE LÍNGUAS PELO VIÉS FUNCIONAL: OS USOS DE BUG, BUFF, LAG E NERF NOS JOGOS DIGITAIS
}

\author{
Michely Gomes Avelar (UEG) \\ Déborah Magalhães de Barros (UEG)
}

Resumo: Este trabalho tem por objetivo refletir como as novas tecnologias, em especial o jogo digital, têm motivado mudanças no uso do português brasileiro. Buscamos apontar os fatores que possibilitaram que os gamers trouxessem para o léxico do português brasileiro os vocábulos lag, bug, nerf e buff e a partir deles provocassem mudanças na língua. Para tal, apoiamo-nos nas teorias da Gramática de Construções (GC) e da Linguística Funcional Centrada no Uso (LFCU) (GOLDBERG, 2006; BYBEE, 2016; TRAUGOTT; TROUSDALE, 2013) no intuito de explicar as regularidades lexicogramaticais emergentes existentes na língua em uso. O corpus desta pesquisa se constitui de ocorrências dos vocábulos buff, bug, lag e nerf e suas variações em posts retirados de contextos de interação da comunidade gamer. A partir da perspectiva da LFCU e da GC, pautando-nos na necessidade de ancorar as práticas linguísticas cotidianas vivenciadas pelos alunos às práticas escolares de ensino de línguas, pretendemos oportunizar-lhes a possibilidade refletir sobre o funcionamento da língua.

Palavras-chave: Linguística Funcional Centrada no Uso; Gramática de Construções; Jogo digital; Ensino do Português Brasileiro; Português Brasileiro.

Abstract: This paper intends to reflect about how new technologies, especially digital games, have been influenced shapes in Brazilian Portuguese Language. We seek to show the mechanisms and motivations that make possible to gamers integrate new items - based on terms lag, bug, nerf and buff - in Brazilian Portuguese Language. We focused on arguments adopting a Constructionist Approach and Used-Based Model of Grammar (GOLDBERG, 2006; BYBEE, 2016; TRAUGOTT; TROUSDALE, 2013) to explain the lexicogrammar structures and units emerging by language in use. The corpus based research consists of occurrences of the words buff, bug, lag and nerf and their variations, in posts interactions of gamer's community. From the perspective of the LFCU 
and the GC, we focus on the need to anchor the daily linguistic practices experienced by the students to the teaching practices of languages, giving students opportunities to reflect on usage-based language.

Keywords: Used-Based Model of Grammar. Constructional Grammar; Digital Game; Brazilian Portuguese language teaching; Brazilian Portuguese.

\section{CONSIDERAÇÕES INCIAIS}

A tecnologia tem conquistado mais espaço em nosso dia a dia. Por meio dela, construímos teias de interação e construção coletiva para expressar nossas ideias, compartilhar e adquirir informações de forma instantânea com pessoas de qualquer lugar do mundo. O jogo digital é um exemplo de recurso tecnológico que se populariza na sociedade contemporânea, sendo que, atualmente, 75,5\% dos brasileiros jogam em algum tipo de plataforma ${ }^{1}$.

O jogo digital propicia interação entre os jogadores de diferentes localidades que se comunicam por meio de uma linguagem especializada. Nesse contexto digital, encontramos muitas palavras em língua inglesa, e muitos jogos digitais não são traduzidos para a língua materna. Assim, muitas vezes, durante o jogo, o gamer não encontra um correspondente satisfatório para a língua portuguesa; deste modo, ele readapta o vocabulário para atender às necessidades comunicativas do jogo.

1 De acordo com dados da Pesquisa Game Brasil 2018. In https://www.pesquisagamebrasil. com.br/. 
Adotando a perspectiva da Linguística Funcional Centrada no Uso (doravante LFCU) e da Gramática de Construções (doravante GC), compreendemos que alguns vocábulos provenientes do mundo digital foram readaptados para o português brasileiro para melhor atender às necessidades comunicativas dos falantes. Tal readaptação se assemelha com uma reanálise, como descreve a GC. Neste sentido, este trabalho surge com o intuito de suscitar uma reflexão sobre os processos de mudanças linguísticas propiciadas pelo contexto digital, considerando que as línguas são dinâmicas, estão em constante processo de mudança e que os falantes utilizam-na para promover a interação social.

Nesta pesquisa, propomos analisar os vocábulos buff, bug, lag e nerf compreendendo a importância de investigar as contribuições das novas tecnologias para o português brasileiro. Consideramos que as reflexões são importantes para o ensino da língua materna, a partir da perspectiva da LFCU e da GC, pautando-nos na necessidade de ancorar as práticas linguísticas cotidianas vivenciadas pelos alunos às práticas escolares de ensino de línguas oportunizando aos alunos compreender as diversidades linguísticas e as situações de uso.

A Base Nacional Curricular preconiza que a língua deve ser compreendida como "fenômeno (geo)político, histórico, 
social, variável, heterogêneo e sensível aos contextos de uso" reconhecendo e compreendendo o seu funcionamento enquanto "fenômeno marcado pela heterogeneidade e variedade de registros, dialetos, idioletos, estilizações e usos muito variados de outras línguas em âmbito global, respeitando o fenômeno da variação linguística, sem preconceitos" (BRASIL, 2018, p.486).

Ensinar a língua associando-a às práticas digitais é uma forma de fazer sentido, mostrar como as transformações acontecem a partir do uso da língua é enriquecer o processo de ensino-aprendizagem e destacar os efeitos sociais e culturais que advêm desse processo. Em relação aos domínios e conhecimentos gramaticais, Barros destaca que o principal objetivo é que

ocorram de maneira integrada, reflexiva e significativa com o conhecimento sobre uso cotidiano da língua, nas suas diversas modalidades e com a consciência de que todas as modalidades prescindem de regularidades estruturais inerentes e necessárias à emergência do textual, adequadas aos diferentes gêneros. (BARROS, 2017, p.94)

Nesta perspectiva, objetiva-se que o ensino da língua propicie uma reflexão sobre a estrutura gramatical e o funcionamento da língua e, oportunizando que, a partir 
do contexto de uso, seja possível analisar linguisticamente a construção de sentidos, as escolhas lexicogramaticais, a função sintática da palavra, a categoria gramatical a que pertence e todos os demais fatores que estão atrelados à língua para que se possa "apreender a língua que, de fato acontece, na imensa heterogeneidade de seus usos e de suas formas" (ANTUNES, 2003, p.151). Deste modo, defendemos que o ensino da língua materna contemple a percepção de "como as categorias e regras gramaticais, na verdade, funcionam na construção dos textos, orais ou escritos, curtos ou longos" (2003, p.124).

O corpus desta pesquisa é constituído por recortes de práticas comunicativas dos gamers em fóruns e redes sociais, portanto, diz respeito ao uso efetivo da língua. Consideramos, para esta pesquisa, o termo gamer com ampla abrangência, abarcando todos os jogadores de jogos eletrônicos independente da frequência e/ou nível de proficiência do jogador. $\mathrm{O}$ trabalho está dividido em duas partes seguidas por algumas considerações. Na primeira parte é uma seção teórica que discorrerá sobre a perspectiva da Linguística Funcional e da Gramática de Construções. Na segunda, traremos algumas reflexões sobre as mudanças linguísticas propiciadas pelas interações digitais a partir da análise dos vocábulos buff, bug, lag e nerf. 


\section{A LÍNGUA EM USO: PRESSUPOSTOS TEÓRICOS}

A gramática de uma língua não pode ser oferecida como uma camisa-de-força, primeiro mapeada para depois ser recheada de exemplos. (NEVES, 2009, p.85)

Sob o viés da Linguística Funcional, a gramática é vista como uma rede de escolhas significativas que estão relacionadas a um padrão estrutural sistêmico, nesta perspectiva, o falante estrutura a produção de significados no nível lexicogramatical, considerando o construto sociocultural ao qual o falante está inserido (nível semântico). Assim, a concepção de língua vai além das classificações gramaticais e que Halliday (2007) define como um complexo sistema semiótico ao qual recorremos para dar sentido às nossas experiências e interagir com as outras pessoas. As escolhas linguísticas realizadas pelos falantes estão relacionadas à organização cognitiva das experiências. Uma vez que a língua é complexa e dinâmica, os falantes usam os recursos existentes na língua para criar novas formas de se expressar. (BYBEE, 2016; HALIDDAY, 2004; TRAUGOTT; TROUSDALE, 2013).

Para que o indivíduo desempenhe determinado papel social, é preciso que ele selecione, organize e sequencie as palavras em forma de um texto que produza significado. Halliday e Matthiessen (2004) afirmam que a linguagem 
constrói a experiência humana e se constitui pela interação social e pela cognição. Apontam que os significados são construídos por meio de metafunções da linguagem: a ideacional, que se divide em experiencial e lógica, que se refere ao processo de nomear, categorizar e classificar as coisas, ou seja, construir experiências; a interpessoal, onde as interações são estabelecidas; e a textual, que é a contextualização e construção de sentidos através do discurso. Assim, no jogo digital, o gamer é motivado pelas demandas discursivas para referenciar o mundo virtual ao qual está inserido.

Durante o jogo digital, é possibilitado ao gamer interagir com outros personagens, construir laços de cooperação, participar de missões, enfrentar desafios, elaborar estratégias, ou seja, ele estará imerso em uma nova realidade da qual outros jogadores inseridos em diferentes culturas fazem parte. Avelar e Freitas (2018) explicam que os gamers precisam dominar a linguagem do jogo para estabelecer comunicação com os demais, e que, para tal, eles se apropriam de elementos culturais e utilizam interações linguísticas variadas para a construção de sentidos. Uma vez que as expressões já existentes na língua nem sempre conseguem expressar situações no ambiente virtual que 
misturam a linguagem e a concepção digital, são criadas novas construções linguísticas para descrever, ou que traduzem essas situações.

A criatividade é um recurso utilizado pelo falante para concretizar a língua, portanto, quando o falante precisa expressar-se e não encontra um item linguístico em sua língua materna ele aciona meios para criar um novo item, sendo a analogia uma destas possibilidades. Deste modo, o gamer usa um novo item, elabora uma nova construção, baseandose no contexto do jogo digital, nas suas experiências de mundo e nas vivências socioculturais e digitais associadas aos modelos mentais e sistemas linguísticos adquiridos cognitivamente (rede de nós). O sujeito usa como recurso inputs dos jogos digitais e as representações esquemáticas da língua. Para explicar o modo como a língua e a gramática se entrelaçam na criação de novas estruturas linguísticas, amparamo-nos na Linguística Funcional Centrada no Uso e na Gramática de Construções, cujo enfoque está relacionado às estruturas das línguas a partir do uso, ou seja, nos contextos comunicativos.

Goldberg (2006) explica o termo Construções como pareamento entre forma e função, ela explica que esse tipo de abordagem enfatiza que as línguas são aprendidas - 
construídas - com base no input, nas restrições cognitivas, pragmáticas e de processamentos gerais. A Linguística Funcional Centrada no Uso (doravante LFCU), que abriga princípios da Linguística Funcional Clássica e da Linguística Cognitiva, aponta que o estudo da língua emerge do uso e, portanto, os fatores extralinguísticos deverão ser considerados. Nessa perspectiva, a gramática da língua se constitui dos padrões regulares no nível dos sons, das palavras e das unidades maiores, dos sintagmas e orações e das formas que emergem desses padrões. A LFCU, portanto, objetiva identificar motivações discursivo-pragmáticas e semântico-cognitivas acionadas ao uso dos padrões (CUNHA; BISPO; SILVA, 2013).

À Gramática de Construções interessa o estudo sobre as mudanças linguísticas que operam tanto no léxico quanto na gramática, para tal, compartilha a concepção da LFCU de que a linguagem é construída e se constrói através dos contextos socioculturais, uma rede de estruturas sistêmicas que o falante tem à disposição e suas escolhas estão vinculadas às suas experiências. Por meio das relações socioculturais, os indivíduos constituem papéis sociais que afetam a forma de se comunicar. Assim, investigar as construções realizadas no ambiente digital trata-se do estudo da língua em uso, 
como um sistema de construção de significados. A expressão da linguagem não é totalmente arbitrária, suas escolhas são motivadas por valores sociais, a partir de elementos prototípicos e com base em estruturas sistêmicas e estruturas de conhecimento armazenadas na memória cognitivamente preexistentes.

Cunha e Lacerda explicam que "a gramática é entendida como conhecimento de um sistema linguístico, como representação cognitiva da experiência dos indivíduos com a língua; portanto ela pode ser afetada pelo uso em situações cotidianas de interação comunicativa" (2017, p.19). Assim, a gramática emerge da língua e se sustenta a partir do uso. A gramática e o léxico não são componentes separados na língua, fazem parte de um único continuum chamado lexicogramática (HALLIDAY; MATTHIESSEN, 2004).

Traugott; Trousdale (2013) apontam que ao processar uma construção o ouvinte aciona pelo input um dos nós em sua rede buscando mecanismos para que possa interpretar. Em algumas situações não haverá nenhum link direto acionado, então recorremos a um ajuste acionando um nó ou recurso existente de um nó, ocasionando em uma inovação para o receptor. No jogo digital há uma palavra para significar uma situação em que o jogo apresenta falhas ou erros que 
atrapalham o bom andamento da jogatina; deste modo, ao tentar encontrar uma palavra em língua portuguesa que pudesse representar significativamente o processo, o falante tenta acionar os nós de sua rede. Na falha de encontrar um correspondente satisfatório, ele aciona outros mecanismos que permitem a criação de bugs, bugar, bugado, bugando.

A organização da língua norteia as organizações gramaticais. A gramática agrega fatores sociais e cognitivos ao conhecimento de um sistema linguístico, ou seja, semântico, morfossintático, fonológico, pragmático. No entendimento de Goldberg, "todos os níveis de análise gramatical envolvem construções: pareamentos armazenados com função semântica, pragmática ou discursiva, expressões idiomáticas, padrões lexicais parcialmente preenchidos e padrões totalmente esquemáticos" (2006, p.5). Uma construção inovadora será simbólica por não estar substancialmente entrincheirada, só se tornarão casos de mudanças se forem repetidamente usadas e se tornem sinais convencionais. (TRAUGOTT; TROUSDALE, 2013). Tal afirmação corrobora a ideia de que o uso da língua interfere na gramática.

Cunha e Lacerda explicam que a Gramática de Construções ocupa-se dos princípios motivadores para cada construção que poderão ser relacionados aos aspectos da "aquisição da 
língua, princípios de gramaticalização, demandas discursivas, princípios icônicos ou princípios gerais de categorização" (2017, p.21):

A construção de conceitos relaciona-se às experiências do ser humano no ambiente biofísico e sociocultural, e são esses conceitos que nos permitem categorizar mentalmente as categorias e raciocinar sobre elas. Cada categoria é conceitualizada em termos do representante prototípico, aquele que reúne os traços recorrentes de que se compõe essa categoria. (CUNHA; BISPO; SILVA, 2013, p.16)

Conforme Ferrari, "categorização é o processo através do qual agrupamos entidades semelhantes (objetos, pessoas, lugares, etc.) em classes específicas" (2016, p.31), ou seja, aquilo que compartilha traços comuns, por exemplo, categorizamos em jogos digitais os jogos de console, smartphones, tablets e computadores, pois são codificados em linguagem binária e são recursos tecnológicos e fonte de entretenimento.

A categorização é um processo cognitivo, já que é criada a partir do estoque mental de experiências linguísticas e extralinguísticas do falante, envolve aspectos fonéticos, morfológicos, associação de significados, ou seja, a memória enriquecida do falante. Lexicalmente, as palavras são categorizadas conforme a sua função e conceito. 
Deste modo, temos as categorias de substantivos, adjetivos, verbos, dentre outras. "Cumpre destacar que para a LFCU, as categorias são fluidas, por isso não há a rígida distinção entre palavras lexicais e gramaticais" (BARROS, 2016, p.43). Cada categoria revela o elemento prototípico, sendo aquele que engloba o maior número de características elencadas na categoria.

O processo no qual os novos enunciados são criados a partir do acionamento de outros enunciados internalizados é chamado de analogia e, em sua maioria, está relacionada com a semelhança semântica ou fonológica entre as formas existentes, "sequência de palavras pré-fabricadas" (BYBEE, 2016). Aplica-se a analogia quando incluímos um novo elemento com base em um padrão existente armazenado cognitivamente. Esse armazenamento acontece por meio da categorização, assim, os exemplares similares se organizam formando uma estrutura prototípica para o falante que por meio da criatividade e servindo-se da analogia evoca um novo item para se expressar, uma nova construção. "A analogia revela-se como a habilidade para expandir posições esquemáticas em construções e o seu preenchimento com novos itens lexicais, sintagmas ou construções" (BYBEE, 2010 apud BARROS, 2016, p.64). 
No jogo digital, o gamer vivencia situações linguísticas, cognitivamente e inconsciente ele internaliza os elementos com base no contexto sociocultural e relações sociais estabelecidas no ambiente do jogo, classifica-os, considerando o que já é prototípico da língua e a partir daí, novas construções poderão ser formadas. Utilizando-se da analogia o falante acrescenta o sufixo desinencial -ar aos vocábulos buff, bug, lag e nerf formando de novos verbos. O processo se deu por analogia aos verbos já existentes na memória rica do falante que compreende o uso de uma flexão morfológica. "Em termos linguísticos, a analogia refere-se ao processo de criação de novos enunciados com base em associações feitas com outros enunciados já existentes em experiências discursivas anteriores" (BARROS, 2016, p.62).

A probabilidade de que uma construção se aplique a um novo item está relacionada à produtividade. Traugott e Trousdale (2013) associam produtividade à frequência da construção: frequência type, número de diferentes expressões que um determinado padrão possui e frequência token, número de vezes que uma mesma unidade se repete no texto. Cunha, Bispo e Silva explicam que

A frequência do uso de uma determinada construção leva a seu estabelecimento no repertório do falante e faz dela uma unidade de processamento, o que implica 
que o falante explora recursos gramaticais disponíveis para atingir seus objetivos comunicativos (2013, p.16)

Entende-se, portanto, que o aumento da frequência de uso significa aumento da frequência da construção, a repetição e automatização são os fatores-chave. Quanto mais o falante utiliza a construção, mais ela se consolida e expande para outros contextos.

\section{BUG, BUFF, LAG, NERF: LÍNGUA EM USO NOS JOGOS DIGITAIS}

Tendo como objetivo investigar as escolhas lexicogramaticais feitas pelos gamers, a pesquisa aborda a língua portuguesa em contexto de uso no ambiente digital de modo a verificar de que forma as relações socioculturais estão sendo afetadas pelo uso das tecnologias, especificamente, dos jogos virtuais. Acreditamos que relacionar a língua em uso ao ensino da língua colabora para compreender como acontece a produção de sentidos e (re)conhecer a língua como um sistema dinâmico e adaptável (NEVES, 2009).

O corpus foi constituído por posts retirados de diferentes fóruns de jogos virtuais online, chats e redes sociais por se tratar de recursos utilizados como meio de interação entre os jogadores. Os gamers, além do jogo digital, utilizam alguns canais digitais, como twitter, facebook, fóruns da 
Blizzard (Empresa desenvolvedora e editora de softwares de entretenimento e criação de jogos digitais), para trocar experiências e outras informações que possam contribuir para o seu desempenho no jogo. Priorizou-se a escolha desses canais por se tratar de situações linguísticas de uso efetivo dos gamers enquanto membros de uma comunidade falante do português brasileiro. Os registros foram utilizados conforme coletados, ou seja, preservando a grafia e caracteres utilizados. Definiu-se para a pesquisa as palavraschave buff, bug, lag e nerf e as variações decorrentes delas considerando que estão inseridas no vocabulário gamer há algum tempo e por terem provocado mudanças linguísticas no português brasileiro que extrapolam o contexto dos jogos digitais.

Palavras de origem inglesa como buff, bug, lag e nerf são comumente usadas no ambiente virtual, seu uso é motivado pelos impactos discursivos e pragmáticos da tecnologia em relação à língua. As escolhas lexicogramaticais do jogador são motivadas pelo mundo digital, ou seja, as relações socioculturais propiciadas pelo jogo, pelas vivências e experiências individuais e coletivas, enfim, por diversos fatores linguísticos e extralinguísticos. Halliday e Matthiessen (2004) explicam que quando falamos ou escrevemos estamos 
produzindo um texto, que se refere a uma instância da língua que faça sentido para alguém que conhece a língua, o que significa que a gramática deve interagir com elementos externos à linguagem. Assim, as comunidades virtuais dos jogos e o universo do jogo digital corroboram ao falante a criação de um vocabulário próprio.

Todavia, a frequência do uso do "novo vocabulário", quando mais consolidado, impulsionará seu uso fora do contexto de jogo. Bybee argumenta que "quanto maior a frequência de type, maior a produtividade ou probabilidade de a construção ser estendida a novos itens" (2016, p.113). Considera-se então que os padrões mais gerais das construções servirão de estruturas simbólicas para novos itens, quanto mais esquemático, maior o número de ocorrências. Já foram incorporados ao nosso vocabulário itens como deletar (delete) e tuitar (twitter), xerocar (xérox) ambos utilizando o sufixo -ar para indicar verbos. Deste modo, o falante estende esse conhecimento internalizado, por ser mais frequente, para criar novos itens.

Consideremos as definições - retiradas dos dicionários online Etymonline e Cambridge Dictionary - dos termos em sentido original:

a) Lag - atraso / to lag - ficar para trás; 
b) Bug - erro, falha, defeito;

c) buff-do inglês buffe, couro de búfalo - é uma gíria para descrever alguém musculoso, em boa forma física;

d) nerf - marca de brinquedos da Hasbro, cujos brinquedos são feitos de um tipo de espuma no intuito de não danificar nem quebrar nada.

No contexto digital, acontece uma expansão no sentido dos termos e mobilidade categorial, ora exercendo papel de verbo, ora de substantivo, ora de adjetivo. Essa mudança de categorias acontece para melhor atender às necessidades comunicativas da língua, desse modo, o falante adequa cognitivamente o vocábulo que transita entre as classes de palavras de acordo com as exigências discursivas. Isso acontece devido à (motivação gramatical), pois algumas vezes a noção expressa pelo verbo deve referenciar um conceito (motivação semântica). Em (1), bug corresponde ao processo de bugar, no sentido de informar que houve uma falha ou que algo estragou inexplicavelmente, assim, a construção elaborada pelo falante exige o uso de um vocábulo correspondente à categoria substantivo.

1. "é um bug, toda vez que tem uma missão que voce recebe um emotevoce precisa reiniciar o client, isso sempre aconteceu comigo" (CAVALCA, 2019). 
De acordo com Neves, o falante realiza as escolhas lexicogramaticais de acordo com as funcionalidades da língua, assim, "não é porque alguém decidiu, num determinado momento, contemplar uma das 'subclasses' de sujeito na Nomenclatura Gramatical Brasileira" (2009, p.120), assim, o uso dos vocábulos buff, bug, lag e nerf como substantivos acontece porque o falante os considera comunicativamente adequados para dar fluidez à informação.

Imerso no jogo digital, o falante se depara com termos em língua inglesa e percebe a necessidade de adequá-los ao português brasileiro para melhor atender suas necessidades comunicativas. Assim, no jogo digital, o termo lag é usado para expressar situações de atrasos na comunicação ou pequenas falhas no jogo que o fazem travar temporariamente; já o vocábulo bug mantém o sentido de erro, falha ou defeito.

Enquanto substantivo preserva a forma original da palavra: 2. “Um bug tem afetado o popular game Fortnite Battle Royale. E para minimizar transtornos, a desenvolvedora Epic Games tomou uma nova medida" (BOTELHO, 2019).

3. "Vocês viram o buff que rolou no Darius que agora ele fica invisível?" (INTZEPORTS, 2019).

4. "Única coisa que deixa a gente agressivo é o $L A G$, o jogo não! \#somosgamersnaoassassinos" (SILVAOGOBO, 2019). 
5. "Na minha opinião esse nerf foi feito pra tirar a Irelia da midlane e fazer com que ela volte a ser uma campeã duelista no top." (EX MAIN IRELIA, 2019).

As palavras não mudam aleatoriamente, o falante recorre aos padrões gerais armazenados na memória e faz associações, assim, ao ser exposto a inputs provocados pelo jogo digital ele se depara com os termos e os categoriza utilizando os conhecimentos de estrutura de sua própria língua. Consideremos, neste caso, que o falante identificou como sintagmas nominais os termos lag, bug, nerf e buff, por se tratarem de vocábulos que dão nome a algo no jogo, logo, ao elaborar um enunciado onde ele possa inserir tais elementos ele identifica a necessidade de um verbo e, em alguns casos, mais argumentos baseado na construção prototípica SN + V + SN. Quando esse sintagma necessita ser flexionado em número, o gamer recorre à regra geral para formação do plural em substantivos que é acrescentar o sufixo $-s$, assim, temos os vocábulos lags, bugs, nerfs e buffs.

Há ainda a flexão para o grau diminutivo com o acréscimo do sufixo -zinho, como mostram os exemplos (6) e (7) no intuito de minimizar a dimensão ou atenuar o discurso. Esse processo se dá por meio da analogia e categorização dado à similaridade ou emparelhamento das palavras com 
as representações armazenadas na memória rica do falante. Trata-se do armazenamento inteligente de possibilidades de aplicação das estruturas da língua, assim, ela é mapeada a partir da "experiência linguística e pela capacidade de associações e inferências entre fatos linguísticos" (BARROS, 2016, p.66).

6. "mano do ceuuu voltei a jogar de akali pq ela teve um buffzinho e to péssima qq taaconteceno" (MINATRANQUILEBA, 2019).

7. "Então mano pode ter rolado um bugzinho reinicie seu cliente, se caso o erro persistir envie um ticket para o suporte do jogador: https://support.riotgames.com/hc/pt-br" (TNEIGHBOURHOOD, 2019).

Quando usado pelos falantes no ambiente virtual, os vocábulos passam pelo processo de mudança de categoria ao ser manifestado por um verbo que designará ação ou processo expresso pelo substantivo (bug e lag) ou, ainda, denotam propriedades, condições ou estado e motivaram a formação de verbos que denotem um processo de mudança (nerfar e bufar). Nos processos de formação verbal as estruturas mais produtivas são por sufixação, sendo as formações em -ar mais frequentes. (BASILIO, 2011). Assim, nerf originará nerfar, que indica mudança de estado de algo 
mais forte para mais fraco, enquanto que buff originará buffar, indicando mudança de estado para aprimoramento, buggar representará a ação de cometer ou causar um bug, e lag originará lagar, que se refere ao atraso na comunicação - por erro ou falha - entre o gamer e o jogo.

Compreender como acontecem as mudanças na língua é relevante para o ensino de língua materna uma vez que possibilitará aos alunos observar que as variações não são aleatórias, e que existem certos padrões que nortearão o uso da língua. Neves postula que o falante,

conduzido na reflexão sobre o uso da linguagem, vai poder orientar-se para a utilização eficiente dos recursos do processamento discursivo, e, a partir daí, chegar a uma sistematização dos fatos da língua legitimada pelo efetivo funcionamento da linguagem. (2009, p.115)

Thompson e Hopper explicam que "o sentido de um verbo ou predicado está relacionado aos esquemas léxicogramaticais em que ele pode ocorrer, e a estrutura argumental é essencialmente um subconjunto desses esquemas" (2001, apud CUNHA; BISPO; SILVA, 2013, p.16).

X AGIR (Construção menos transitiva)

X AGIR Y (Construção mais transitiva)

Aconstrução instanciada nos usos dos verbos apresentados no contexto do jogo virtual consiste de: 


$$
\begin{array}{ll}
\mathrm{SN}+\mathrm{V}+\mathrm{SN} & \mathrm{SN}+\mathrm{V}+\varnothing \\
\text { Arg1 }+\mathrm{V}+\text { Arg2 } & \text { Arg1 }+\mathrm{V}
\end{array}
$$

Os verbos lagar, bugar, nerfar e buffar poderão integrar sentenças menos transitivas, sendo o sujeito da sentença agente ou afetado, como no exemplo (8), principalmente nas construções relacionadas ao jogo digital, pois se pressupõe que o recurso digital seja a causa ou consequência, não sendo necessário selecionar outro argumento para compreensão. De forma prototípica, os verbos lagar e bugar são menos transitivos, enquanto nerfar e buffar são mais transitivos.

8. "Free fire bugou, evento cancelado e todo mundo indignado" (STEFANYDOROTEU, 2019).

Os verbos também podem construir sentenças mais transitivas, como em (9), exigindo a seleção de dois ou mais argumentos: Argumento 1 (sujeito causativo ou afetado) + Verbo (ação ou processo) + Argumento 2 (afetado ou não afetado).

9. “\#LeagueOfLegends: A Riot Games voltou atrás e já buffou a Neeko On Hit de volta!" (MAISESPORTSBR, 2019).

O uso do vocábulo bug, em todas as suas categorias, está mais consolidado que os demais, sendo, portanto, encontrado em diversas outras construções, como mostram os exemplos (10) a (14), que vão além do jogo digital. As operações 
cognitivas expandem o sentido dos vocábulos indexados ao português brasileiro e possibilitam seu uso metaforizado em outras situações expressando a ideia de confundir ou não entender algo. É possível encontrar também construções com o vocábulo lag, como em (11), em contextos que não estão relacionados ao ambiente digital, mas que preservam mesma carga semântica.

10. “Quem nunca foi na casad@amig@e se ferrou porque pegou aquele controle todo bugado?" (PARISFILMES, 2019).

11. "o dia foi meio bugado hoje" (ELYELSON, 2019).

12. “Agora bugou o cérebro. Jamais pensei, mas já quero ela abraçando a família aqui fora. Tá cada vez mais difícil assistir isso! \# \#bbb19" (NAHFIR, 2019).

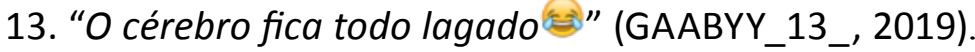

Como mostram os exemplos, os falantes, a partir de suas experiências linguísticas, constroem novos exemplares que poderão ser convencionalizados na medida em que os falantes usam a língua. Barros explica que

quando uma mudança faz que um padrão de uso se torne regular e se fixe no sistema linguístico, ocorre uma alteração na gramática da língua, por isso, a Linguística Funcional Centrada no Uso assume a dinamicidade da gramática, moldada em função do uso. (2016, p.38)

É importante observar que o contexto digital, e, nesta perspectiva, os jogos digitais, motiva processos de mudanças 
linguísticas que são, no entendimento de Bybee (2016), necessários para compreensão da estrutura da língua.

\section{ALGUMAS CONSIDERAÇÕES}

Percebemos que no contexto digital os gamers se expressam por meio de linguagem especializada, cujas escolhas lexicogramaticais se relacionam com as experiências criadas pelo jogo, pela comunidade digital, influências socioculturais. A comunicação empregada pelos gamers é constituída por manifestações criadas pela necessidade de interação no ambiente virtual, no contexto do jogo digital.

Considerando que, na perspectiva da Linguística Funcional Centrada no Uso e na Gramática de Construções, a língua é um pareamento entre forma e função, o léxico e a gramática não podem ser vistos separadamente. $O$ presente estudo justificou-se pelo fato de que a língua é dinâmica e emerge do uso e, portanto, provoca mudanças linguísticas. Com base na LFCU, buscamos "explicar as regularidades observadas no uso interativo da língua analisando as condições discursivas em que se verifica esse uso" (CUNHA; COSTA; CEZARIO, 2015).

O processo analógico motiva fortemente a criação de novos itens e isso acontece porque o falante tem a sua disposição uma rede de enunciados internalizados disponíveis ao qual criativamente associa suas representações cognitivas e os 
padrões de estrutura linguística. As mudanças na língua acontecem motivadas pelas necessidades comunicativas, portanto, quando o falante não encontra em sua rede de nós um enunciado adequado para expressar-se, ele cria um novo item. Esse novo item não é criado aleatoriamente, ele é pautado nos elementos cognitivos alinhados aos sistemas linguísticos e ao acionamento dos padrões estruturais.

A partir da análise dos dados, concluímos que os jogos digitais, bem como os recursos tecnológicos, têm incitado mudanças linguísticas na medida em que impactam na reconfiguração das formas de comunicação. Deste modo, verificamos que os itens lexicais buff, bug, lag e nerf propiciaram a criação de conteúdos lexicogramaticais para o português brasileiro em diferentes categorias. Verificouse que a formação das palavras seguiu o padrão prototípico da língua, sendo que os substantivos conservam a forma original; os verbos são conjugados regularmente; e as construções transitam entre $[S N+V+S N]$ e $[S N+V+\varnothing]$.

Compreendemos que o meio digital propicia que os falantes criem novos meios de produção de sentido. Isso acontece porque os interagentes exercem não apenas o papel de leitores, mas de produtores da comunicação. Entendemos que não há como dissociar os jogos digitais, bem como as novas tecnologias, da contemporaneidade, portanto, é importante que as práticas linguísticas propiciadas pelos jogos digitais 
sejam integradas ao processo de ensino e aprendizagem. Explicar aos alunos o processo pelo qual novos vocábulos são criados e como as construções se organizam a partir de suas próprias experiências é (re)significar o processo de ensino e aprendizagem. Deste modo, os alunos poderão adquirir consciência linguística quanto às regularidades da língua, à compreensão do funcionamento da língua e suas variedades, e, assim, reduzir o distanciamento entre a língua formal e a língua em uso bem como compreender que fatores sociais e culturais motivam novas práticas linguísticas.

Esperamos, futuramente, realizar uma investigação mais aprofundada acerca dos usos e mudanças decorrentes do jogo digital no intuito de conhecer os padrões construcionais fortemente ligados às escolhas discursivas dos gamers e ao contexto digital.

\section{REFERÊNCIAS}

ANTUNES, Irandé (2003). Aula de português: encontro \& interação. São Paulo: Parábola Editorial.

AVELAR, Michely Gomes; FREITAS, Carla Conti de (2018). "Gameplay, walkthrough e let'splay: um olhar para a cibercultura na educação". In: TEIXEIRA, Zenaide Dias; KOCHHANN, Andréa; PORTO, Marcelo Duarte. Educação, gestão e tecnologias: caminhos entrelaçados. Curitiba: Editora CRV.

BAGNO, Marcos; CASSEB-GALVÃO, Vânia (2017). "Mudança linguística fenômeno sociocognitivo de base funcional". In: BAGNO, Marcos; CASSEBGALVÃO, Vânia; REZENDE, Tânia Ferreira. (Org.). Dinâmicas funcionais da mudança linguística. São Paulo: Parábola Editorial. p.09-33. 
BASILIO, Margarida (2011). Formação e classes de palavras no português do Brasil. 3.ed. São Paulo: Contexto.

BARROS, Déborah Magalhães de (2017). "O estudo escolar da voz na língua portuguesa a partir de uma visão funcionalista". In: Eleone Ferraz de Assis (Org). Caminhos para a educação linguística. Campinas, SP: Pontes Editora, p.91-120.

BARROS, Déborah Magalhães de (2016). Um estudo pancrônico da voz reflexiva em perspectiva. 176f. Tese de Doutorado em Letras e Linguística - Faculdade de Letras, Universidade Federal de Goiás. Goiânia.

BOTELHO, Wellington (2019). "Bug no fortnite preocupa Epic Games e desenvolvedora toma nova medida". Metro jornal. Estilo de vida, São Paulo, p.1. In https://www.metrojornal.com.br/estilo-vida/2019/03/14/ bug-no-fortnite-preocupa-epic-games-e-desenvolvedora-toma-novamedida.html Acesso em 26.Mar.2019.

BRASIL (2018). Base Nacional Comum Curricular: Ensino Médio. Brasília: MEC/Secretaria de Educação Básica.

BYBEE, Joan (2016). Língua, uso e cognição. Maria Angélica Furtado Cunha (Trad.). São Paulo: Cortez.

CAVALCA. [fórumBlizzard]. In https://forum.br.leagueoflegends.com/ t5/Suporte/HELP-PERGUNTAS-DO-URFeA/m-p/472110/highlight/ true\#M58765 Acesso em 12.Mar.2019.

CUNHA, Maria Angélica F. da; BISPO, Edvaldo B.; SILVA, José H. (2017). "Linguística Funcional Centrada no Uso: conceitos básicos e categorias analíticas". In: OLIVEIRA, Mariangela R. de; CEZARIO, Maria Maura. (Org.). Funcionalismo linguístico: diálogos e vertentes. Niterói - RJ: Eduff. p.13-38. CUNHA, Maria Angélica F. da; COSTA, Marcos Antônio; CEZARIO, Maria Maura (2015). "Pressupostos teóricos fundamentais". In: CUNHA, Maria Angélica F. da; OLIVEIRA, Mariangela R. de; MARTELOTTA, Mário Eduardo. Linguística funcional: teoria e prática. São Paulo: Parábola Editorial. p.21-47 CUNHA, Maria Angélica F. da; LACERDA, Patrícia Fabiane A. da C. (2017). "Gramática de construções: princípios básicos e contribuições". In: OLIVEIRA, Mariangela R. de; CEZARIO, Maria Maura. (Org.). Funcionalismo linguístico: diálogos e vertentes. Niterói - RJ: Eduff. p.17-46. 
ELYELSON7. [Tweet]. In https://twitter.com/Elyelson7/ status/1102795477370765319 Acesso em 22.Mar.2019.

EXMAINIRELIA. [fórumBlizzard]. In https://forum.br.leagueoflegends. com/t5/Mec\%C3\%A2nicas-de-Jogo/Nerf-da-Irelia/td-p/446074/page/2 nAcesso em 10.Fev.2019

FERRARI, Lilian (2016). Introdução à linguística cognitiva. São Paulo: Contexto.

GAABYY_13_. [Tweet]. In https://twitter.com/gaabyy_13_/ status/1106243785103757313 Acesso em 20Mar.2019.

GOLBERG, Adele E (2006). Constructions at work: the nature of generalization in language. Oxford: Oxford University Press.

HALLIDAY, Michael A. K; MATTHIESSEN, Christian M. I. M (2004). An introduction to functional grammar. 3ed. London: Hodder Arnold.

INTZESPORTS. [Tweet]. In https://twitter.com/intzesports/ status/1062058312009728008 Acesso em 24mar.2019

MAISESPORTSBR. [Tweet]. In https://twitter.com/maisesportsbr/ status/1106719020974252032 Acesso em 22.Mar.2019.

MINATRANQUILEBA [Tweet]. In https://twitter.com/volpiando/ status/1105826712955310080 Acesso em 15.Mar.2019

NAHFIR. [Tweet]. In https://twitter.com/NahFir/ status/1106374985378160640 Acesso em 20.Mar.2019.

NEVES, Maria Helena de Moura (1994). Uma visão geral da gramática funcional. Alfa, São Paulo, n.38, p.109-127.

NEVES, Maria Helena de Moura (2009). Que gramática estudar na escola? Norma e uso na língua portuguesa. São Paulo: Contexto.

PARISFILMES. [Tweet]. In https://twitter.com/ParisFilmes/ status/1016026668132159489 Acesso em 22.Mar.2019.

STEFANYDOROTEU. [Tweet]. In https://twitter.com/StefanySiilva22/ status/1104524252869521409 Acesso em 15.Mar.2019.

TNEIGHBOURHOOD [fórum Blizzard]. In https://forum. br.leagueoflegends. com/t5/Suporte/HELP-PERGUNTAS-DO-URFeA/m-p/472110/highlight/ true\#M58765 Acesso em 20.Fev.2019. 
TRAUGOTT, E; TROUSDALE, G. (2013). Constructionalization and constructional changes, Oxford, Oxford University Press.

Michely Gomes Avelar é Mestranda programa de Pós-graduação Stricto Sensu em Língua, Literatura e Interculturalidade (POSLLI), no Campus Cora Coralina. Possui graduação em Letras: Português, Inglês e respectivas Literaturas pela Pontifícia Universidade Católica de Goiás (2012). Atualmente, desenvolve pesquisas nas áreas dos novos letramentos e tecnologias digitais. Tem experiência na área de Letras, com ênfase em Línguas Estrangeiras Modernas, atuando principalmente nos seguintes temas: Linguagem e Educação, Letramentos (Novos Letramentos, Multiletramentos, Letramentos Críticos), Formação de Professores, Jogos digitais, Língua Inglesa, Língua e cultura.

E-mail: mg.avelar@hotmail.com

Déborah Magalhães de Barros é Doutora em Linguística pela Universidade Federal de Goiás; possui Mestrado em Linguística pela Universidade Federal de Goiás, Pós-Graduação em História pela Universidade Estadual de Goiás e Graduação em Letras Português e Inglês pela Faculdade de Filosofia Cora Coralina. Realizou estágio Pós-Doutoral na UFG, onde foi professora colaboradora no Programa de Pós-Graduação em Letras e Linguística. Atualmente é professora titular de Linguística e Língua Portuguesa na Universidade Estadual de Goiás, Campus Cora Coralina, onde é diretora de Campus (2018-2021) e atua no Programa de PósGraduação Stricto-Sensu em Língua, Literatura e Interculturalidade. É coordenadora adjunta, no diretório do CNPq, do Grupo de estudos funcionalistas: análise, descrição e ensino e pesquisadora do grupo Rede de estudos da língua portuguesa ao redor do mundo e subprojeto: 0 português brasileiro em contexto italiano. É membro do Grupo Descrição do Português/ANPOLL.

E-mail: deborah_magalhaes@hotmail.com 